\title{
Construction of Bispecific Aptamer-Drug Conjugate by a Hybrid of Chemical and Biological Approach
}

Yang Sun ${ }^{\dagger}$, Fei Gao ${ }^{\dagger}$, Cai Yang ${ }^{\dagger}$, Yingying $\mathrm{Li}^{\ddagger}$, Cheng Jin ${ }^{\ddagger}$, Sitao Xie ${ }^{\ddagger}$, Cheng $\mathrm{Lv}^{\dagger}$, Ding Ding ${ }^{\dagger}$, Da Han $^{\dagger}$, Juan Li†, Ruowen Wang ${ }^{*}, \dagger$ and Weihong Tan ${ }^{*},+, \neq, \S$

Institute of Molecular Medicine (IMM), Renji Hospital, Shanghai Jiao Tong University School of Medicine, and College of Chemistry and Chemical Engineering, Shanghai Jiao Tong University, Shanghai 200240, China.

\$Molecular Science and Biomedicine Laboratory (MBL), State Key Laboratory of Chemo/Biosensing and Chemometrics, College of Chemistry and Chemical Engineering, College of Biology, and Aptamer Engineering Center of Hunan Province, Hunan University Changsha, Hunan 410082, China.

$\S$ Institute of Cancer and Basic Medicine (IBMC), Chinese Academy of Sciences, The Cancer Hospital of the University of Chinese Academy of Sciences, Hangzhou, Zhejiang 310022, China 
General information

Synthesis of compound 2

Preparation of primers

Table S1

PCR condition optimization

Construction of ApDCs

Cell culture

Binding affinity test

Confocal microscopy Imaging

Cytotoxicity assay

NMR spectra of compound 2

Mass spectra of ApDCs 


\section{General information}

Unless otherwise noted below, all commercially available reagents and solvents were purchased from Sigma Aldrich and used without further purification. NMR spectra were recorded on a Bruker AM300 or Bruker AM400 spectrometer. DNA synthesis and mass spectra were performed by Sangon Biotech. Bovine serum albumin (BSA) and yeast tRNA were purchased from Sigma Aldrich. Agarose and Cell counting kit 8 (CCK-8) were purchased from Beyotime Biotech. Streptavidin-coated sepharose beads was purchased from GE Healthcare.

\section{Synthesis of compound 2:}

$\mathrm{N}$-diisopropylchlorophosphoramidite was added (130 $\mathrm{mg}, 0.55 \mathrm{mmol}$ ) dropwise to a solution of 10-hydroxy camptothecin 1 (100 mg, $0.27 \mathrm{mmol}$ ) and DIEA (105 mg, $0.81 \mathrm{mmol})$ in dry $\mathrm{CH}_{2} \mathrm{Cl}_{2}(5 \mathrm{~mL})$ at $0^{\circ} \mathrm{C}$. The mixture was heated to $40{ }^{\circ} \mathrm{C}$ until the solution became clear. When the starting material was consumed, as shown by TLC, the reaction was diluted with $\mathrm{CH}_{2} \mathrm{Cl}_{2}(20 \mathrm{~mL})$ and washed with saturated sodium bicarbonate and saturated saline. After drying over anhydrous sodium sulfate, the solution was concentrated, and the residue was purified by flash column giving phosphoramidite 2 as a yellow solid (78 mg, 52\% yield); $\left.{ }^{1} \mathrm{H} \mathrm{NMR} \mathrm{(400} \mathrm{MHz,} \mathrm{CDCl}_{3}\right) \delta$ $8.28(\mathrm{~s}, 1 \mathrm{H}), 8.16(\mathrm{~d}, J=8.9 \mathrm{~Hz}, 1 \mathrm{H}), 7.66(\mathrm{~s}, 1 \mathrm{H}), 7.60(\mathrm{~s}, 1 \mathrm{H}), 7.56(\mathrm{~s}, 1 \mathrm{H}), 6.32(\mathrm{~s}, 1 \mathrm{H})$, $5.74(\mathrm{~d}, J=16.2 \mathrm{~Hz}, 1 \mathrm{H}), 5.30(\mathrm{~d}, J=16.2 \mathrm{~Hz}, 1 \mathrm{H}), 5.27(\mathrm{~s}, 2 \mathrm{H}), 4.22-4.13(\mathrm{~m}, 2 \mathrm{H})$, 4.06-4.0 (m, 1H), 4.00-3.93 (m, 1H), 3.85-3.75 (m, 2H), 3.55-3.49 (m, 2H), $1.29(\mathrm{~d}, J=$ $7.0 \mathrm{~Hz}, 12 \mathrm{H}), 1.04$ (t, J = $7.4 \mathrm{~Hz}, 3 \mathrm{H}) ;{ }^{31} \mathrm{P} N \mathrm{NMR}\left(162 \mathrm{MHz}, \mathrm{CD}_{3} \mathrm{Cl}\right) \delta 146.9$.

\section{Preparation of primers}

Primer P1 (Table S1) as a 21mer incorporated with 3 units of 5-FU was ordered from Takara.

Primer P3 (Table S1) was prepared by automated synthesis with phosphoramidite

2.

Primer P4 (Table S1) was prepared by the reaction of 20mer 5'- SH- 
T(T-FAM)-TTTTTTATCTAACTGCTG-3' with vcMMAE. First, vcMMAE was dissolved in acetonitrile to give a $2 \mathrm{mM}$ solution, and $200 \mu \mathrm{M}$ aqueous solution of the $20 \mathrm{mer}$ was prepared. Then $300 \mu \mathrm{L}$ primer solution and $100 \mu \mathrm{L}$ vcMMAE solution were added to a reaction buffer $\left(100 \mu \mathrm{L} 400 \mathrm{mM} \mathrm{KCl}, 150 \mu \mathrm{L}\right.$ acetonitrile, $\left.50 \mu \mathrm{L} \mathrm{H}_{2} \mathrm{O}\right)$ and the mixture was kept at room temperature for 8 hours. The reaction product was isolated by HPLC followed by lyophilization and was identified to be P4 by mass spectrometry.

Table S1. Related sequences.

\begin{tabular}{|c|c|}
\hline Number & Sequence $\mathrm{e}^{(\mathrm{a})}$ \\
\hline P1 & 5'-FAM-(5FU) (5FU) (5FU)-TTTTTTTATCTAACTGCTG-3' \\
\hline P2 & 5'-Biotin-TCTAACCGTACAGTATTT-3' \\
\hline P3 & 5'-(СРT)-FAM-TTTTTTTATCTAACTGCTG-3' \\
\hline P4 & 5'-(MMAE)-T(T-FAM)-TTTTTTTATCTAACTGCTG-3' \\
\hline P5 & 5'-Biotin-GAAACAGAAAAAACAAC-3' \\
\hline Sgc8 & 5'-FAM-TTTTTTAATCTAACTGCTGCGCCGCCGGGAAAATACTGTACGGTTAGA-3' \\
\hline $\mathrm{C} 1$ & 5'-FAM-TAAAGGGCGGGGGGTGGGGTGGTTGGTAGTTGTTTTTTCTGTTTC-3' \\
\hline BsAp & $\begin{array}{l}\text { 5'-FAM-TTTTTTATCTAACTGCTGCGCCGCCGGGAAAATACTGTACGGTTAGATTT } \\
\text { TTTAAAGGGCGGGGGGTGGGGTGGTTGGTAGTTGTTTTTTCTGTTTC-3' }\end{array}$ \\
\hline Lib & $\begin{array}{l}5^{\prime}-F A M-N N N N N N N N N N N N N N N N N N N N N N N N N N N N N N N N N N N N N N N N N N N N N N N \\
\text { NNN-3' }\end{array}$ \\
\hline ApDC1 & $\begin{array}{l}\text { 5'-FAM-(5FU) (5FU) (5FU)-TTTTTTATCTAACTGCTGCGCCGCCGGGAAAATACTGTAC } \\
\text { GGTTAGA-3' }\end{array}$ \\
\hline ApDC2 & 5'-(CPT)-FAM-TTTTTTTATCTAACTGCTGCGCCGCCGGGAAAATACTGTACGGTTAGA-3' \\
\hline ApDC3 & $\begin{array}{l}\text { 5'-(MMAE)-T(T-FAM)-TTTTTTAATCTAACTGCTGCGCCGCCGGGAAAATACTGTACGG } \\
\text { TTAGA-3' }\end{array}$ \\
\hline ApDC4 & $\begin{array}{l}\text { 5'-FAM-(5FU) (5FU) (5FU)-TTTTTTATCTAACTGCTGCGCCGCCGGGAAAATACTGTACGG } \\
\text { TTAGATTTTTTAAAGGGCGGGGGGTGGGGTGGTTGGTAGTTGTTTTTTCTGTTTC-3'3 }\end{array}$ \\
\hline ApDC5 & $\begin{array}{l}\text { 5'-(MMAE)-T (T-FAM)- TTTTTTATCTAACTGCTGCGCCGCCGGGAAAATACTGTACGG } \\
\text { TTAGA TTTTTTAAAGGGCGGGGGGTGGGGTGGTTGGTAGTTGTTTTTTCTGTTTC-3' }\end{array}$ \\
\hline
\end{tabular}

(a) (5FU), (CPT) and (MMAE) represent drug unit synthesized from commercially available 5FU phosphoramidite, phosphoramidite 2 and vcMMAE respectively.

\section{PCR condition optimization}

PCR-related conditions, such as Tm, cycle number, primer concentration, were 
optimized. For each pair of primers, two or more different temperatures were tested near the recommended $\mathrm{Tm} .5 \mu \mathrm{L}$ template $(10 \mu \mathrm{M}), 80 \mu \mathrm{L}$ dNTP, $100 \mu \mathrm{L}$ primers $(100 \mu \mathrm{M}), 100 \mu \mathrm{L} 10 \times$ Taq buffer and $5 \mu \mathrm{L}$ Taq DNA polymerase (TakaRa) were mixed with ultrapure water to a final volume of $1 \mathrm{~mL}$. Then the $1 \mathrm{~mL}$ mixture was aliquoted into $2050 \mu \mathrm{L}$ reactions in PCR tubes and subjected to 30-50 thermal cycles using a Bio-Rad DNA Engine. Each cycle included 30 s denaturation at $95^{\circ} \mathrm{C}, 30$ s annealing at relevant $\mathrm{Tm}$, and 10 s elongation at $72^{\circ} \mathrm{C}$.

\section{Construction of ApDCs}

With optimized PCR conditions, ApDCs were prepared from corresponding primers by the enzymatic reaction. PCR product $(1 \mathrm{~mL})$ was incubated with $300 \mu \mathrm{L}$ streptavidin-coated sepharose beads (GE Healthcare) at $4^{\circ} \mathrm{C}$ overnight. After treating with $500 \mu \mathrm{L} 0.2 \mathrm{M} \mathrm{NaOH}$ for 2 minutes, ApDCs were separated from dsDNA. Finally, after desalting with desalting column (GE Healthcare) and lyophilization, ApDCs were produced, which was confirmed by mass spectrometry.

a)

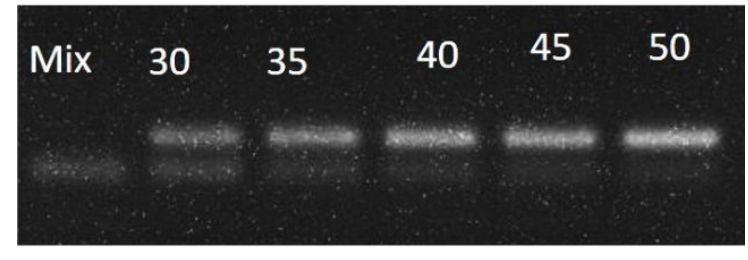

b)

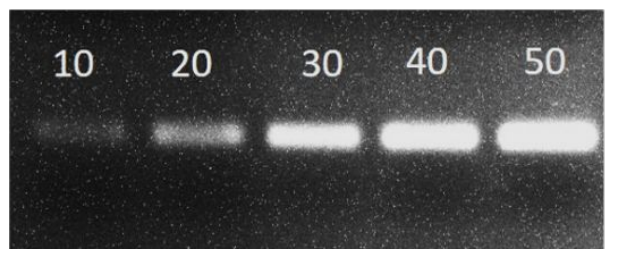

Figure S1. Agarose gel analysis of ApDCs. a) Gel analysis of the PCR product in different cycles; b) Gel analysis of the PCR product with different primer concentration.

\section{Cell culture}

HCT116 cells and NCM460 cells were purchased from ATCC and maintained at $37^{\circ} \mathrm{C}$ in a humid atmosphere with $5 \% \mathrm{CO}_{2}$ and in RPMI-1640 medium supplemented with $10 \%$ fetal bovine serum (Gibco). 


\section{Binding affinity test}

Binding affinity of ApDCs were studied by flow cytometry analysis (Beckman counter, Cytoflex). First, NCM460 cells were prepared with $0.2 \%$ EDTA at $3 \times 10^{5}$ cells/200 $\mu \mathrm{L}$ for each sample. Cells were incubated with 250nM FITC labeled library (Lib), template (sgc8, BsAp) or ApDC in $200 \mu \mathrm{L}$ binding buffer $(500 \mathrm{~mL}$ DPBS, $5 \mathrm{mM}$ $\mathrm{MgCl}_{2}, 4.5 \mathrm{~g} / \mathrm{L}$ glucose, $0.1 \mathrm{mg} / \mathrm{mL}$ yeast tRNA, $1 \mathrm{mg} / \mathrm{L} \mathrm{BSA}$ ) respectively at $4{ }^{\circ} \mathrm{C}$ for 30 minutes. After incubating, cells were washed twice with washing buffer $(500 \mathrm{~mL}$ DPBS, $5 \mathrm{mM} \mathrm{MgCl} 2,4.5 \mathrm{~g} / \mathrm{L}$ glucose), and filtered with $500 \mu \mathrm{L}$ binding buffer before analysis with flow cytometric. NCM460 cells only was used as negative control and DNA library were used as the controls for aptamers.
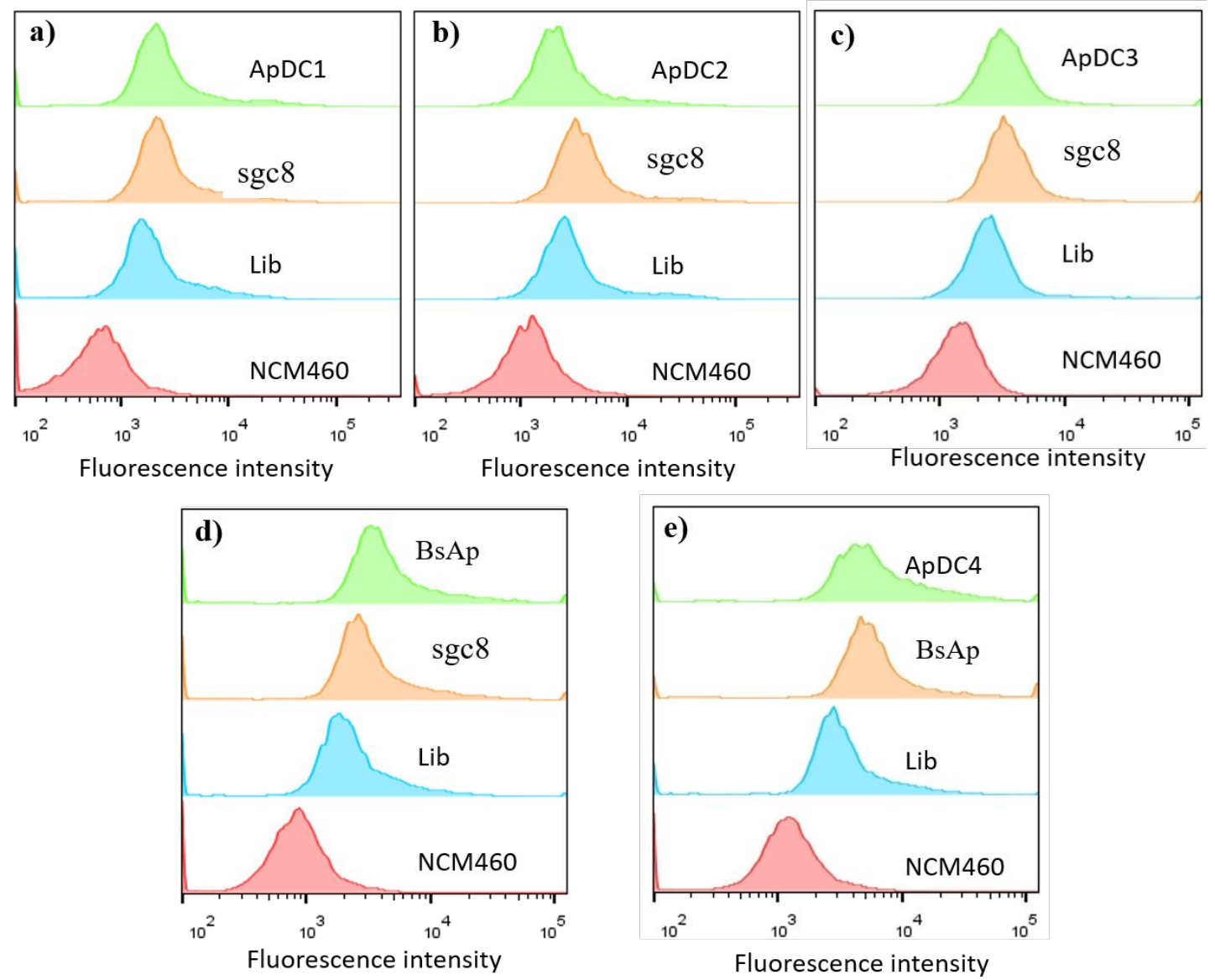

Figure S2. Binding ability of ApDCs test with flow cytometer. a) Binding ability of ApDC1 to control cell NCM460; b) Binding ability of ApDC2 to NCM460 cell; c) 
Binding of ApDC3 with NCM460 cell; d) Binding ability of sgc8 and BsAp with NCM460 cell; e) Binding ability of ApDC4 to NCM460 cell.

\section{Confocal microscopy Imaging}

HCT116 cells were seeded in glass bottom confocal dishes at a density of $1 \times 10^{5}$ per well and allowed to grow overnight. After washing with DPBS, 250nM aptamer $\mathrm{R} 50$ (C1) or sgc8 or BsAp (sgc8-R50) was incubated with cells respectively in binding buffer at $37^{\circ} \mathrm{C}$ for $1 \mathrm{~h}$. Then followed by washing with washing buffer cells were visualized by confocal microscopy (Leica SP8).
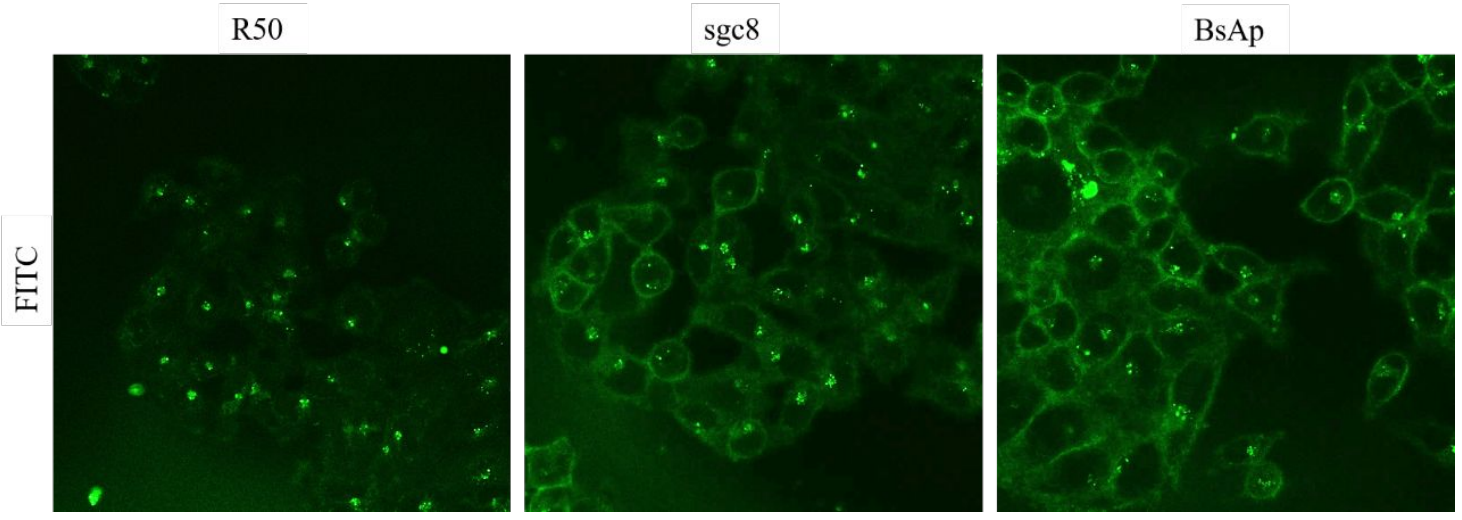

Figure S3. Internalization of aptamers and BsAp. Confocal test the internalization of FITC labeled different aptamer, sgc8 and R50 (C1) were used as control to test the internalization of bi-specific aptamer BsAp (sgc8-R50).

\section{Cytotoxicity assay}

HCT116 cells or NCM460 cells were seeded at $1 \times 10^{4}$ cells/well in 96 -well plates (Corning) and allowed to grow for 24 hours. Different concentrations of samples (drugs/aptamer/ApDC) were mixed with culture medium and added to each well. After incubated at $37^{\circ} \mathrm{C}$ for $48 \mathrm{~h}$, cells were assayed for viability by monitoring the absorbance at 450nM with a multidetection plate reader (Biotek, Synergy H1) using CCK-8. 
a)

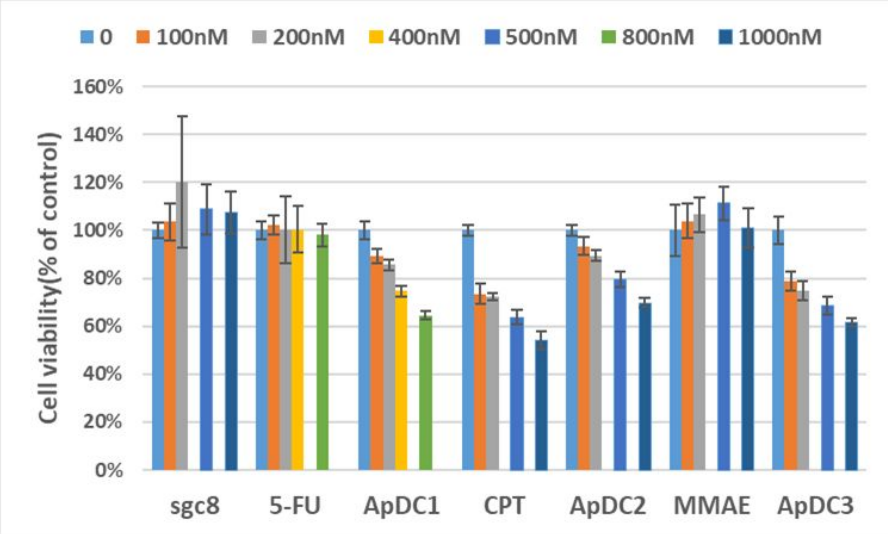

b)

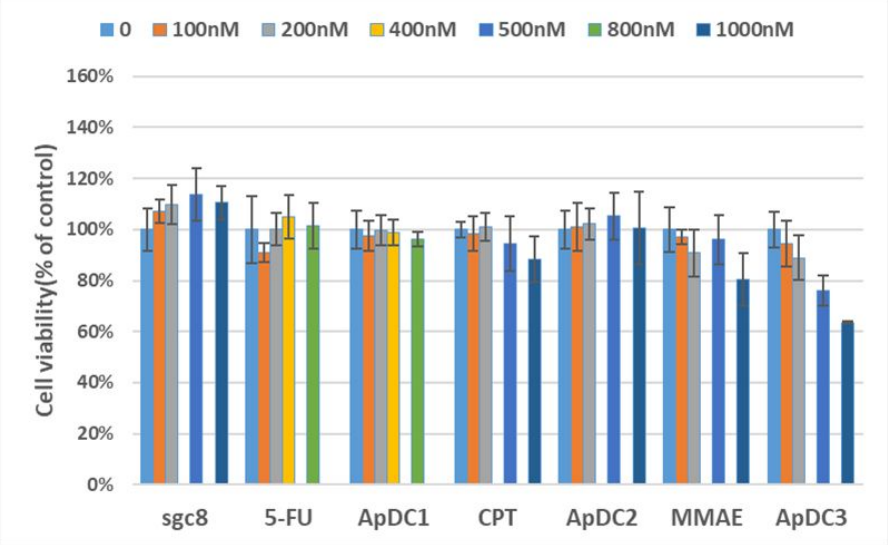

Figure S4. Cytotoxicity test of ApDCs with CCK-8. a) Cytotoxicity of ApDC1, ApDC2 and ApDC3 to HCT116 cell, with template sgc8 and drugs(5-FU/CPT/MMAE) as control; b) Cytotoxicity of ApDC1, ApDC2 and ApDC3 to NCM460 cell, sgc8 and drugs (5-FU/CPT/MMAE) were used as control. 
NMR spectra of compound 2

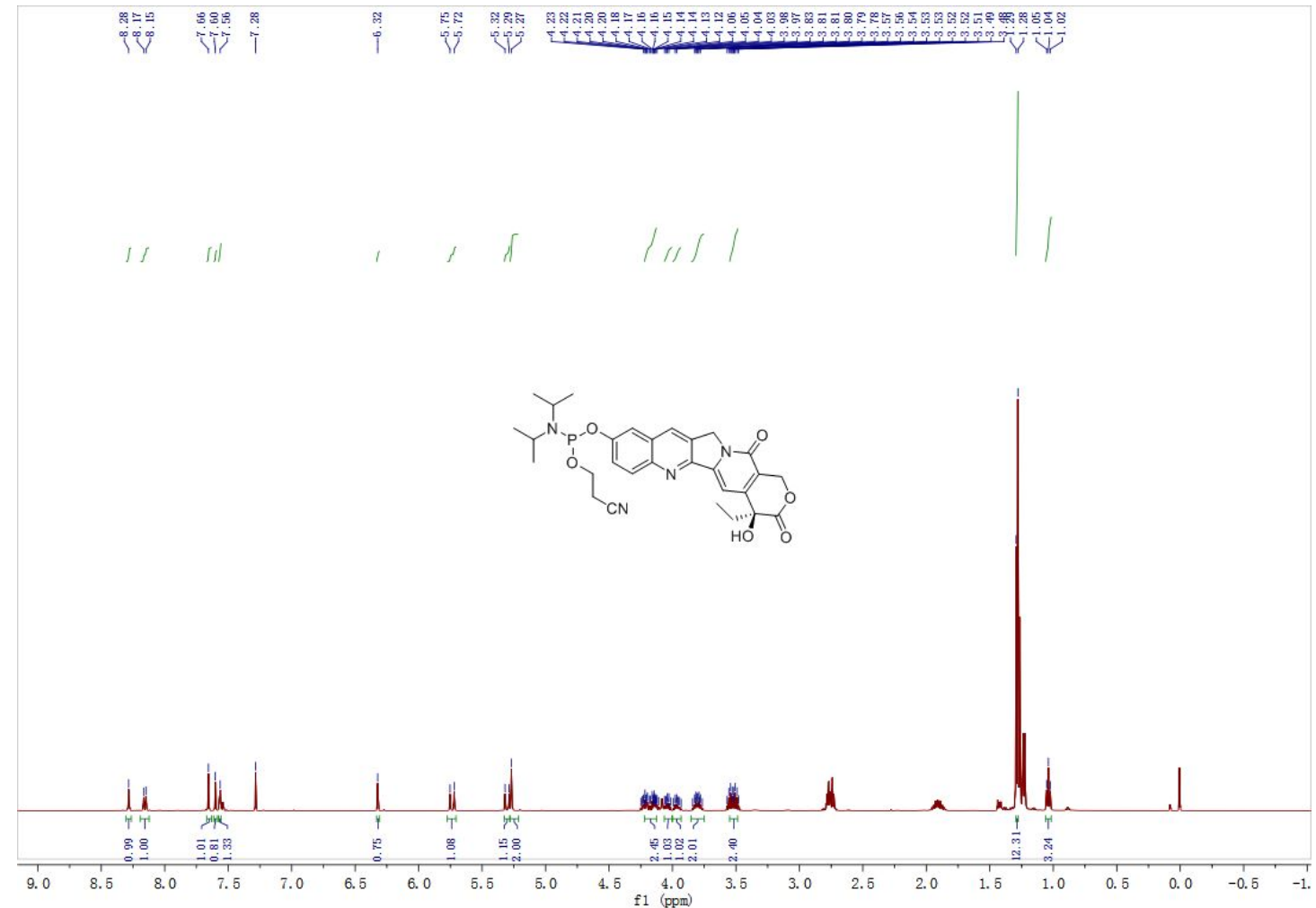

${ }^{1} \mathrm{H}$ spectrum of Phosphoramidite 2

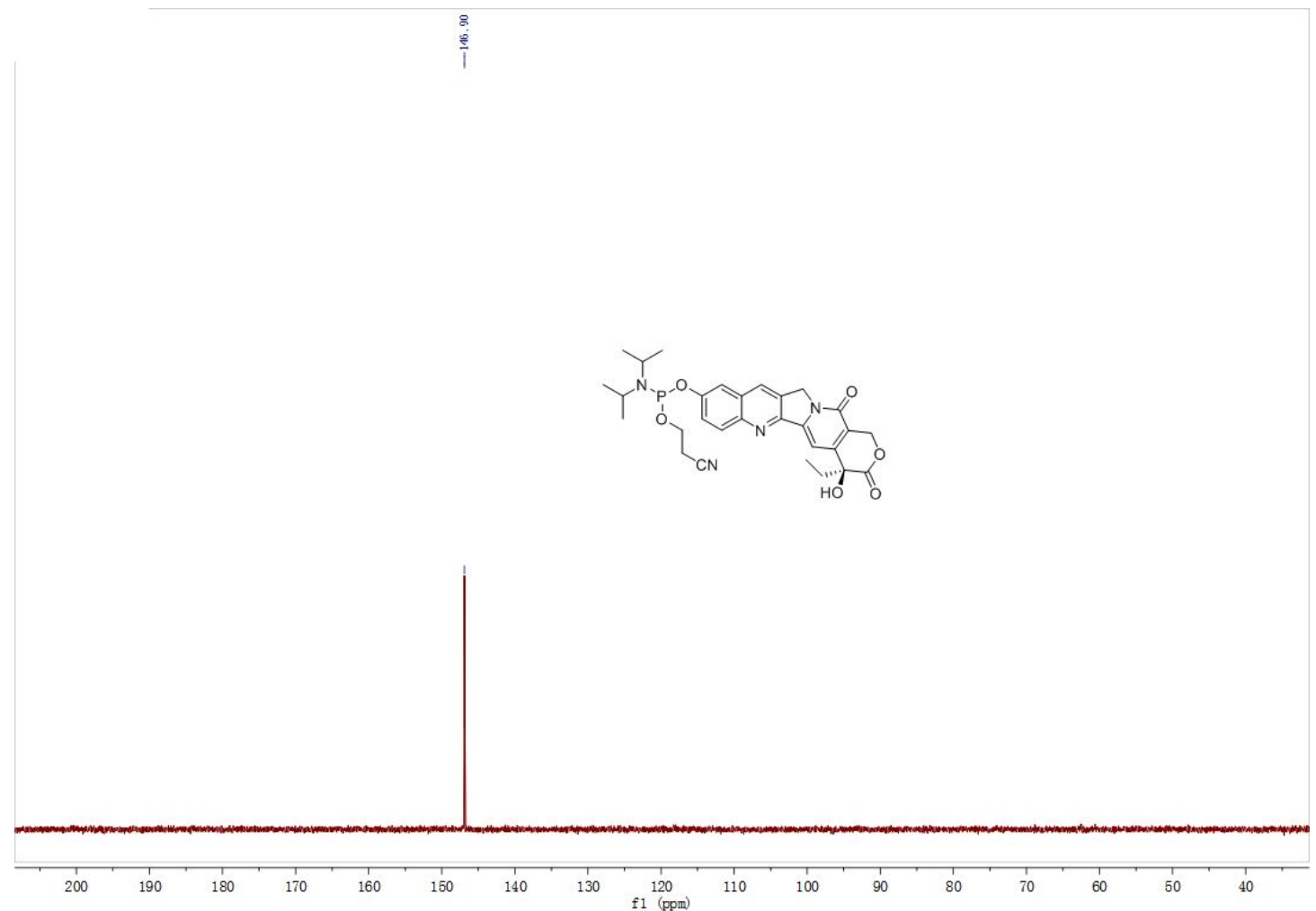

${ }^{31} \mathrm{p}$ spectrum of Phosphoramidite 2 


\section{Mass spectra of ApDCs}

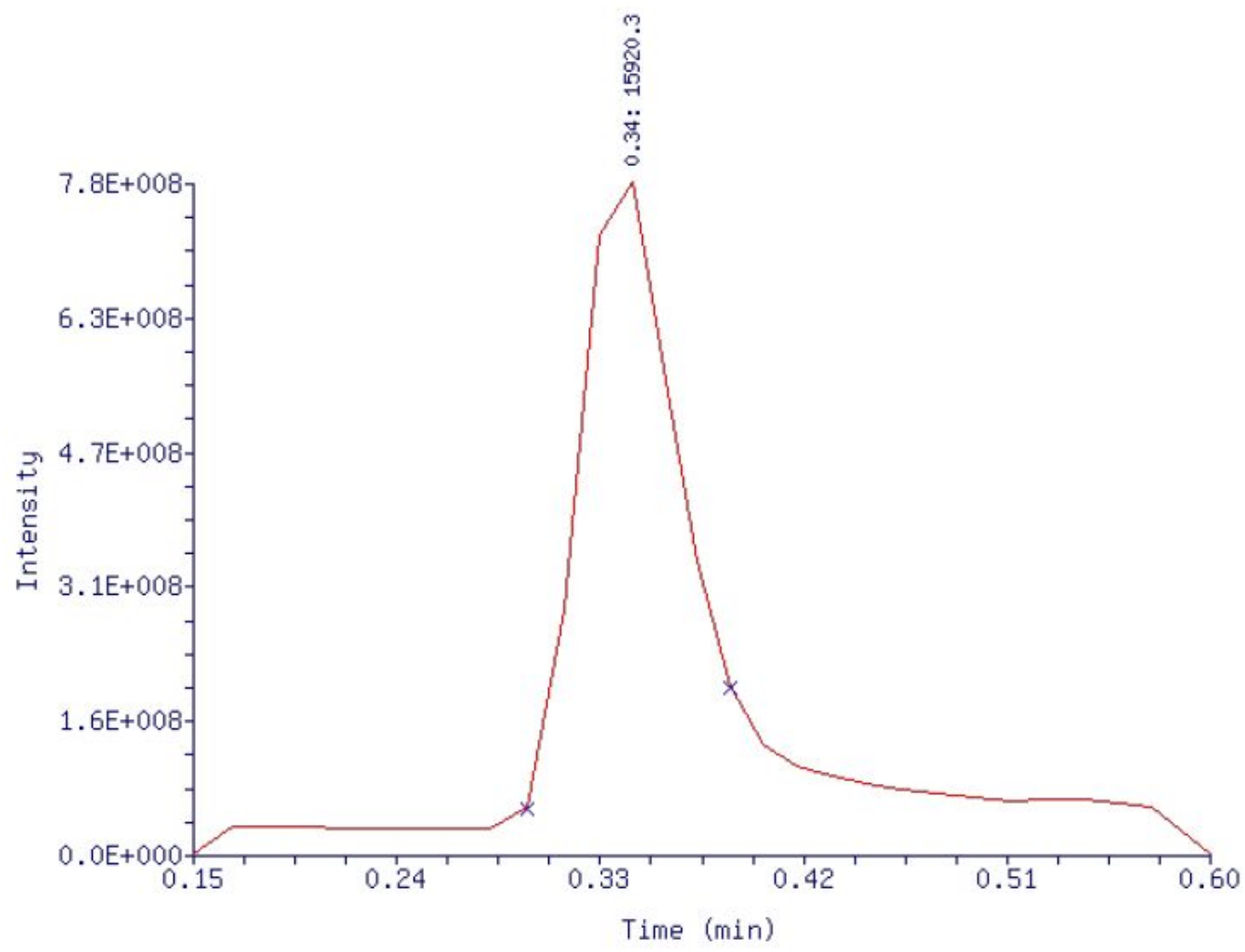

Mass spectrum of ApDC1 (Calculated mass:15921).

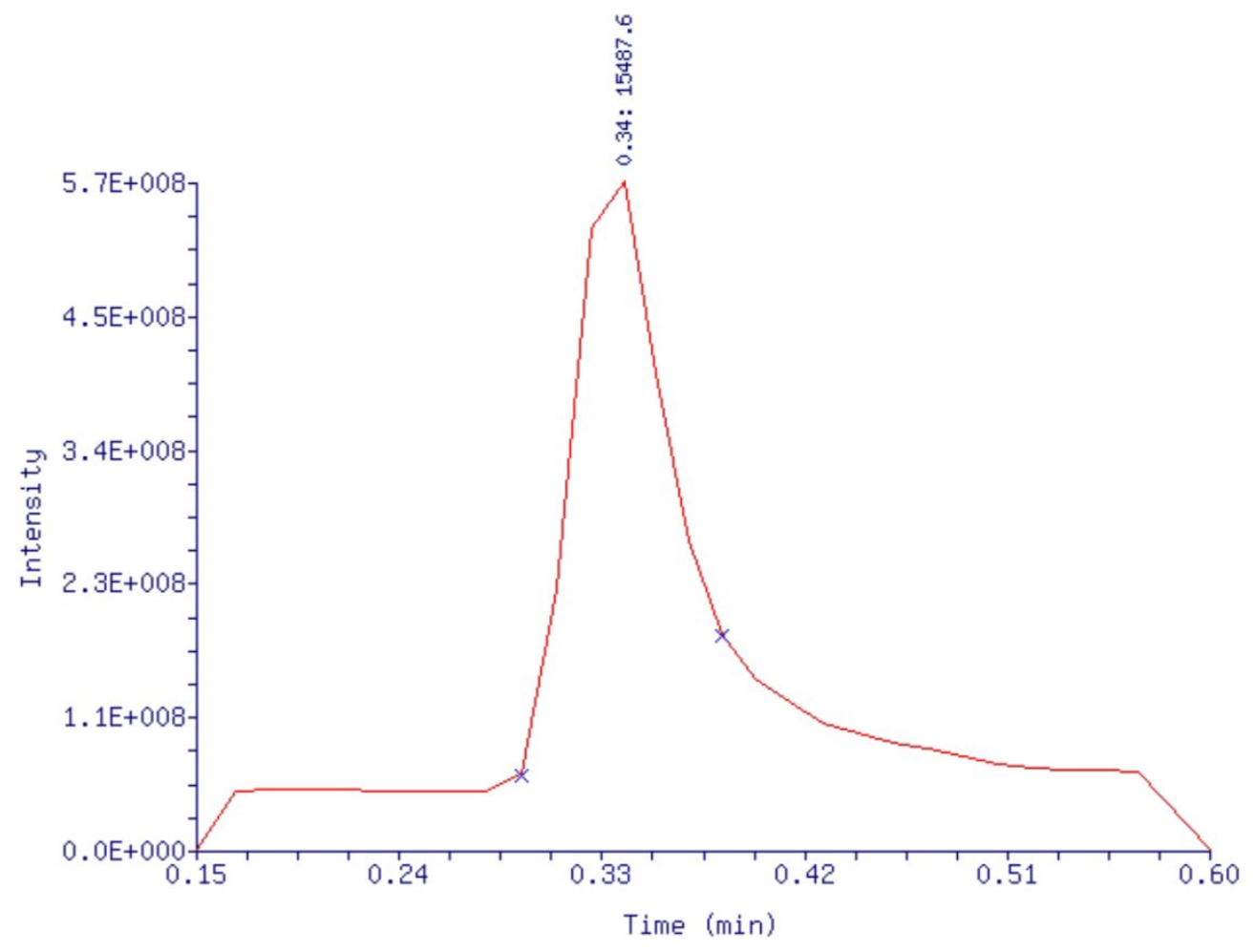

Mass spectrum of ApDC2 (Calculated mass: 15483). 


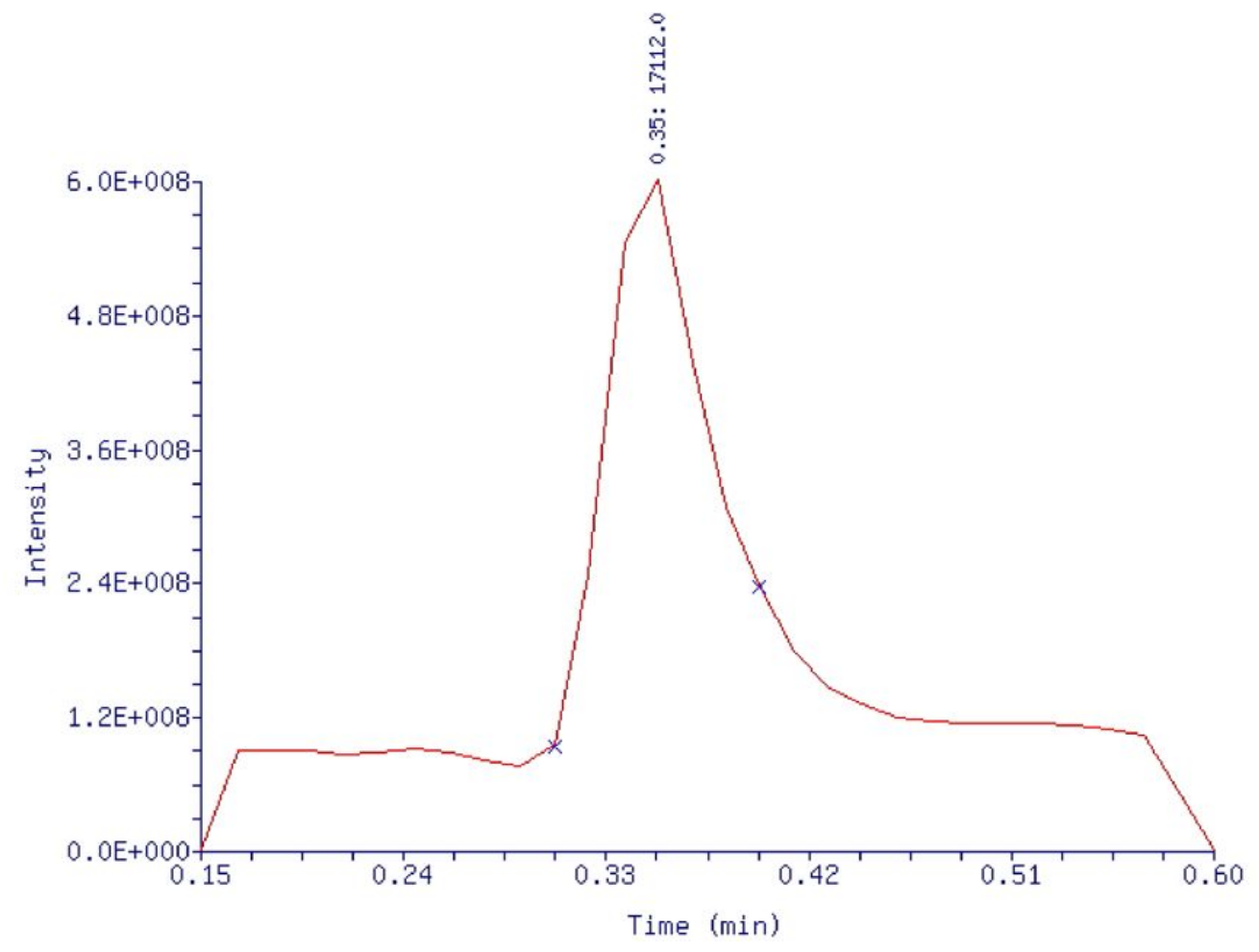

Mass spectrum of ApDC3 (Calculated mass: 17102.2). 